Supplement of Saf. Nucl. Waste Disposal, 1, 249-250, 2021

https://doi.org/10.5194/sand-1-249-2021-supplement

(C) Author(s) 2021. CC BY 4.0 License.

Supplement of

\title{
State-of-Knowledge and Guidance in EURAD Knowledge Management (Work Packages 11 State-of-Knowledge \& 12 Guidance)
}

\author{
Astrid Göbel et al. \\ Correspondence to: Astrid Göbel (astrid.goebel@bge.de)
}

The copyright of individual parts of the supplement might differ from the article licence. 


\section{eurad

\section{STATE-OF-KNOWLEDGE \& GUIDANCE IN EURAD KNOWLEDGE MANAGEMENT (Work Packages 11 State-of-Knowledge \& 12 Guidance)}

10/11/2021• Astrid Göbel, Tobias Knuuti, Jiří Faltejsek, WP11 \& 12 Team 


\section{EURAD KNOWLEDGE MANAGEMENT \& NETWORKING PROGRAMME}

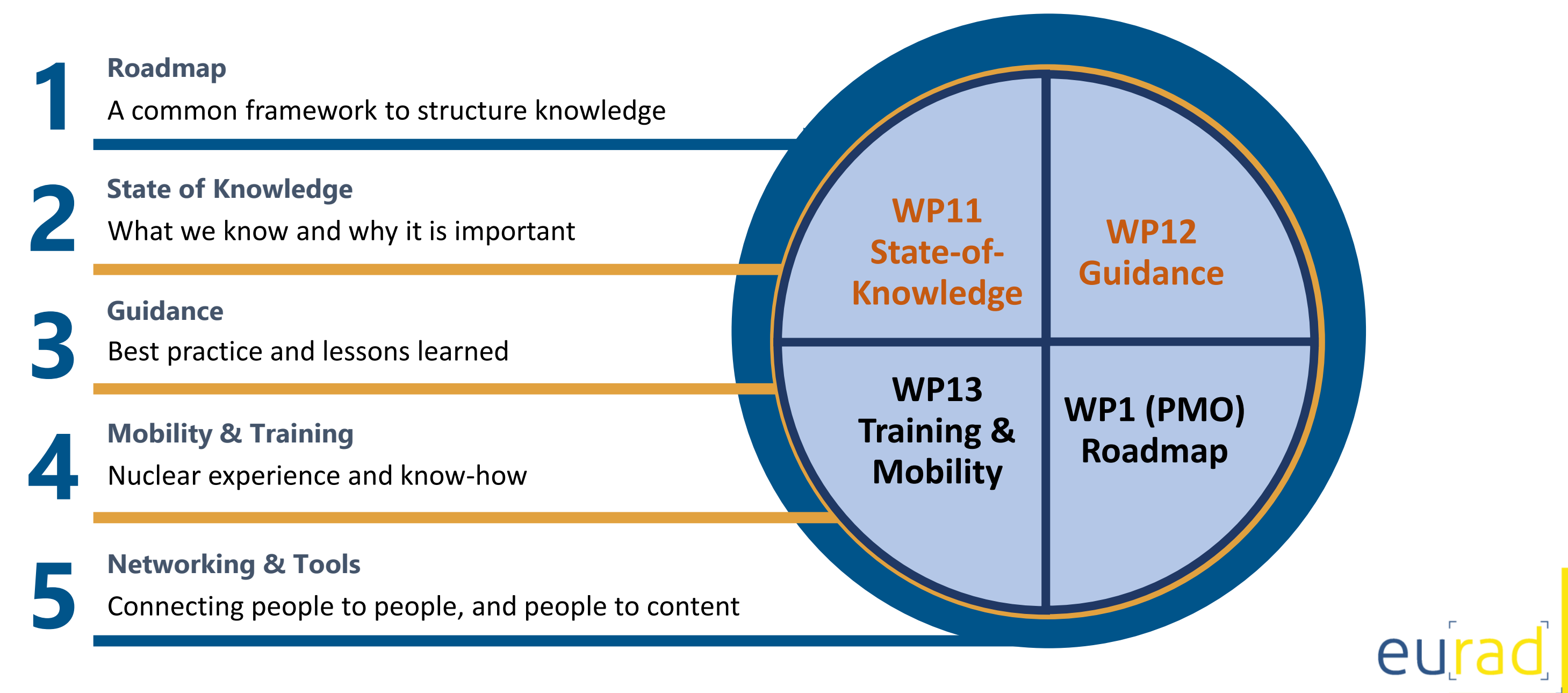




\section{EURAD KNOWLEDGE MANAGEMENT \& NETWORKING PROGRAMME}

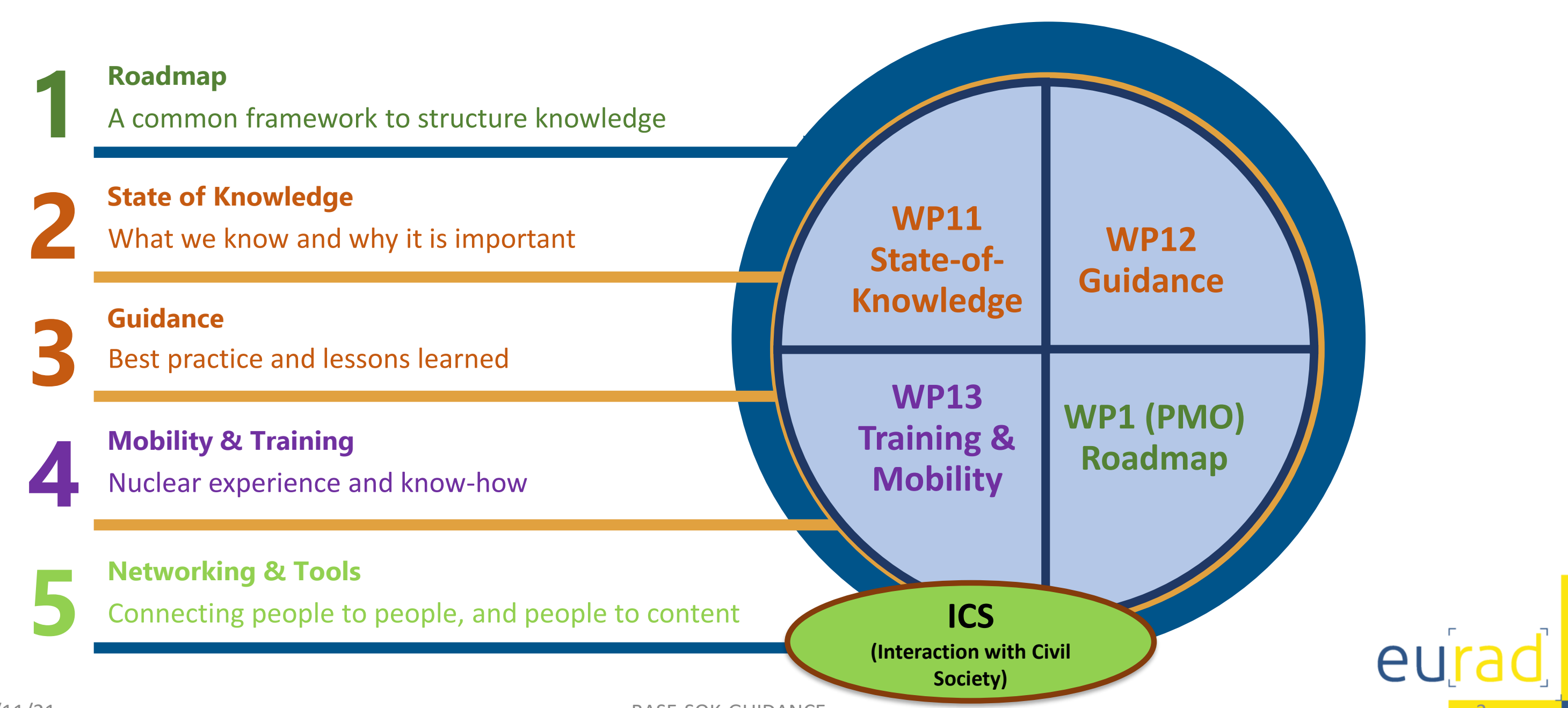




\section{WP11 STATE-OF-KNOWLEDGE + WP12 GUIDANCE - GOALS}

- Capture relevant Knowledge and Expertise to support implementation of RWM

- Generation of documents (KM Documents)

- Well structured and thoroughly managed, but agile and needs oriented

- Concise documents to give an overview / entry point to the topics

- Documents authored by experts

- Systematic approach to Dissemination

- Procedures, clearly defined quality plans

- IT-Tools

- Learning from experienced KM actors (for instance: study in WP11)

- Remaining flexible to adapt to needs and improvements

- User friendly, adequate to fulfil long-term vision

- No redundancies (e.g. IAEA, OECD/NEA) 


\section{SCOPE OF DOCUMENTS BASED ON EURAD ROADMAP}
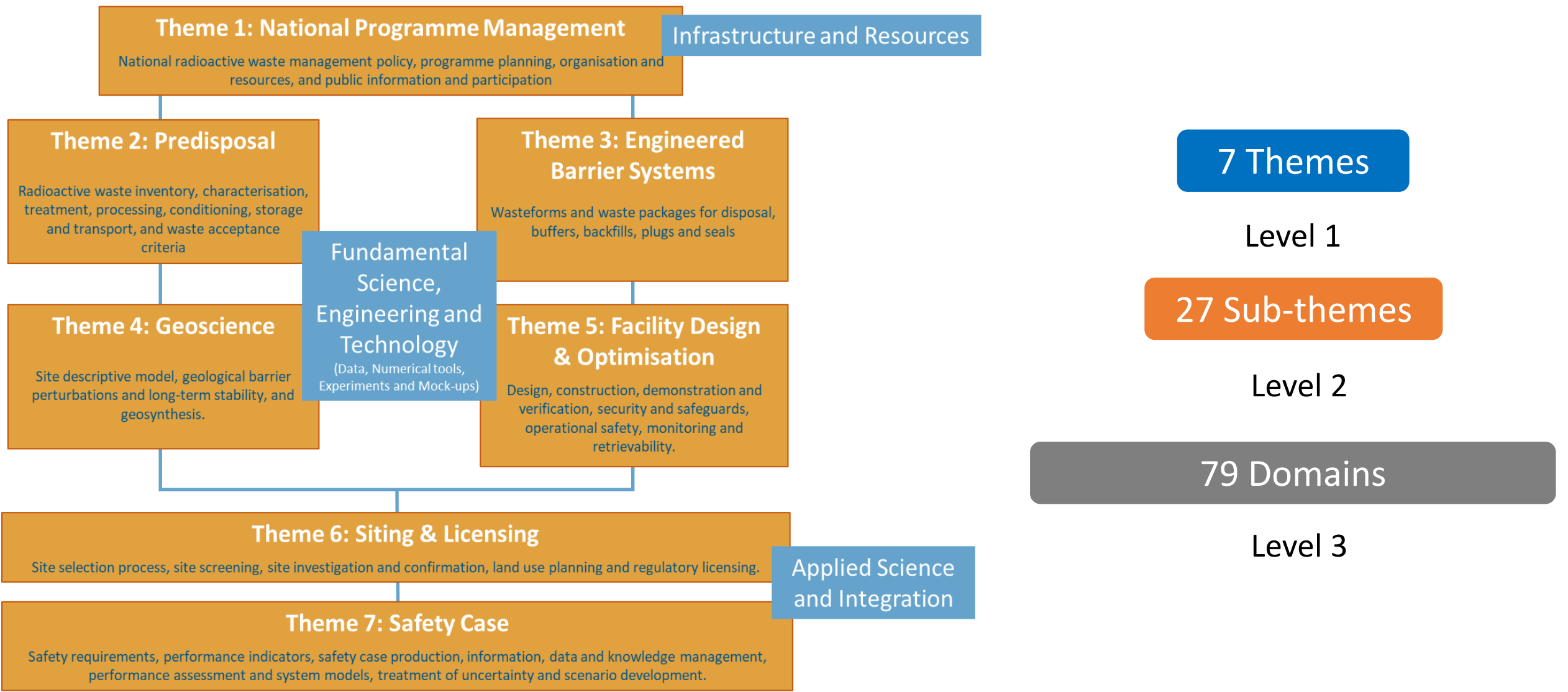

This provides a framework within which to look inside and see whether sufficient information and knowledge exists (knowledge management), or whether additional RD\&D is needed 


\section{EXAMPLE OF ROADMAP STRUCTURE}

\section{Theme 3 Goals Breakdown Structure: Engineered Barrier Systems (Level 1)}

3. Develop an engineered barrier system, tailored to the characteristics of the waste and compatible with the natural (geological) barrier, that performs its desired functions for the long-term disposal of radioactive waste (EBS)

\section{Sub-themes (Level 2)}

3.1 Confirm wasteform

compositions, properties and

disposal conditions, including

radionuclide inons including

and impact on the disposa

the disposal

(3.

3.2 Identify container

materials and designs for

each wasteform under

storage and disposal

conditions and confirm

evolution under storage and

disposal conditions (Waste

packages, for disposal) ?

3.3 Identify appropriate buffer,

backfill and sealiplug

materials and designs, and

confirm their properties.

behaviour and evolution for

the selected repository

concept (Buffers, backfills,

plugs and seals)

\section{Domains (Level 3)}

3.1.1 Spent nuclear fuel (SNF)

3.1.2 Vitrified HLW (HLW)

3.1.3 Cemented LL-ILW (Cemented LL-ILW)

3.1.4 Bituminized waste, ceramics, polymers (Other wasteforms)

3.2.1 HLW and SF containers (HLW and SF Containers)

3.2.2 LL-ILW containers (LL-ILW Containers)

3.2.3 Containers using advanced materials (Novel Containers)

3.3.1 Buffer components under storage and disposal conditions (Buffers)

3.3.2 Backfill components under storage and disposal conditions (Backfills)

3.3.3 Plug and sealing components under storage and disposal conditions (Plugs and seals)

3.4 Confirm integrated EBS

system understanding and

identify compatible EBS

designs and materials for

facilities containing multiple

10/11 wasteforms (EBS system

3.4.1 Confirm complete and integrated EBS system understanding, including the design of an optimized interface EBS/repository and the understanding of the interaction with the repository nearfield environment (EBS system)

3.4.2 Confirm that interactions between different EBS materials in disposal areas for different waste types do not compromise the performance of the 


\section{KM DOCUMENT STRUCTURE}

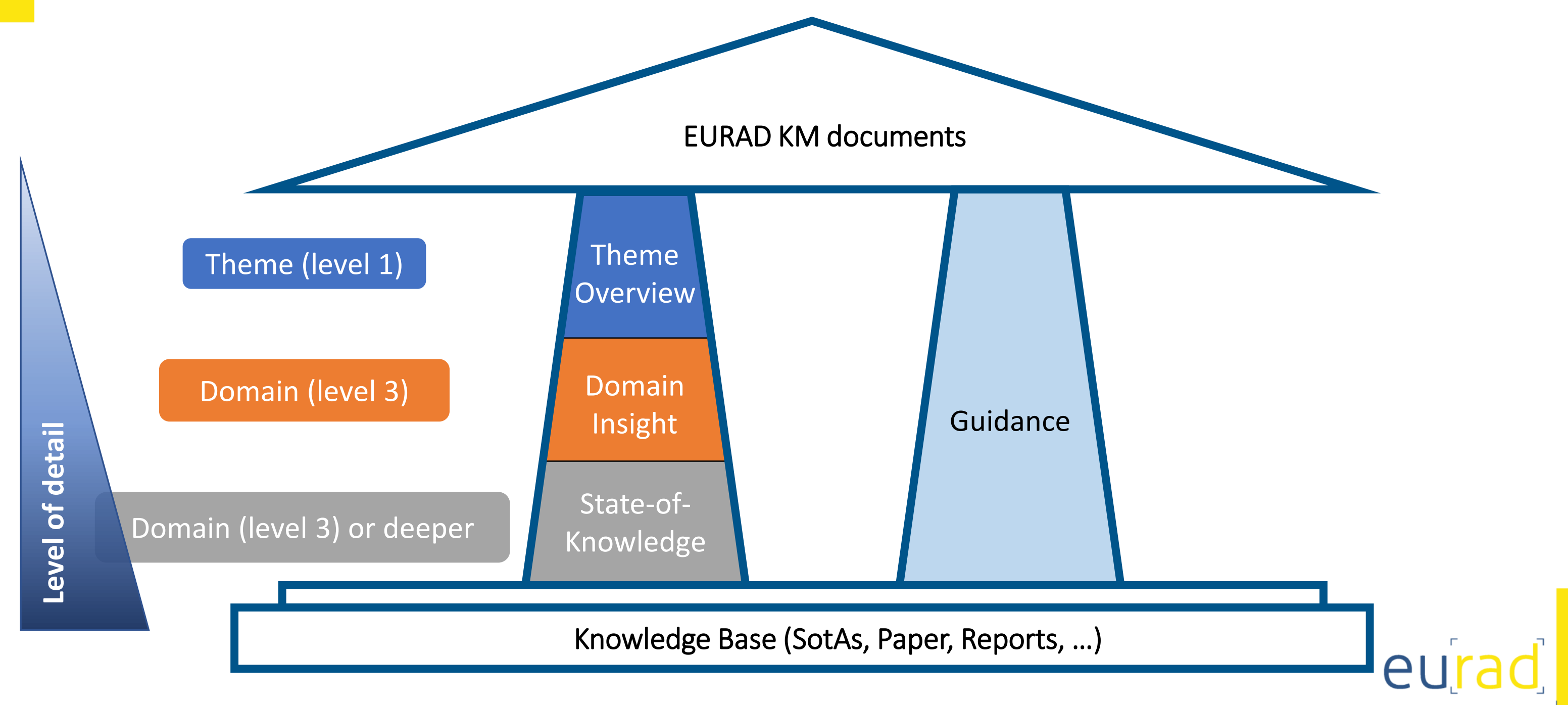




\section{GUIDANCE DOCUMENTS}

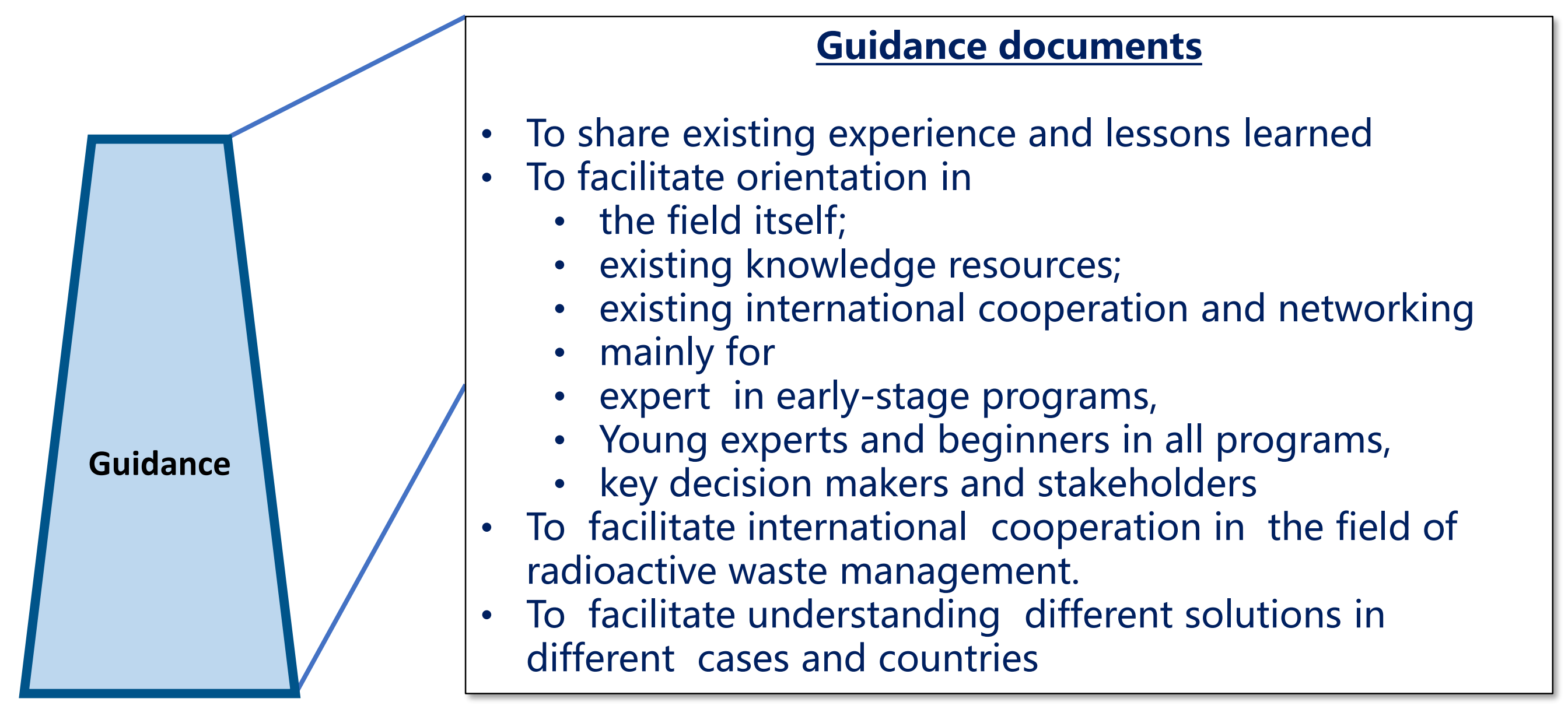




\section{GUIDELINE SELECTION PROCESS IN EURAD}

\section{EURAD Pilot \\ guide \\ preparation \\ experience \\ EURAD Road map goal break down structure \\ Analysis of existing guidelines}

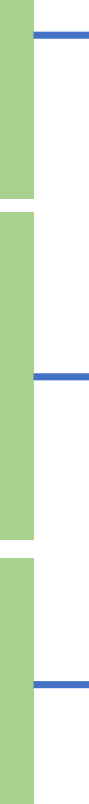

Input from potential endusers
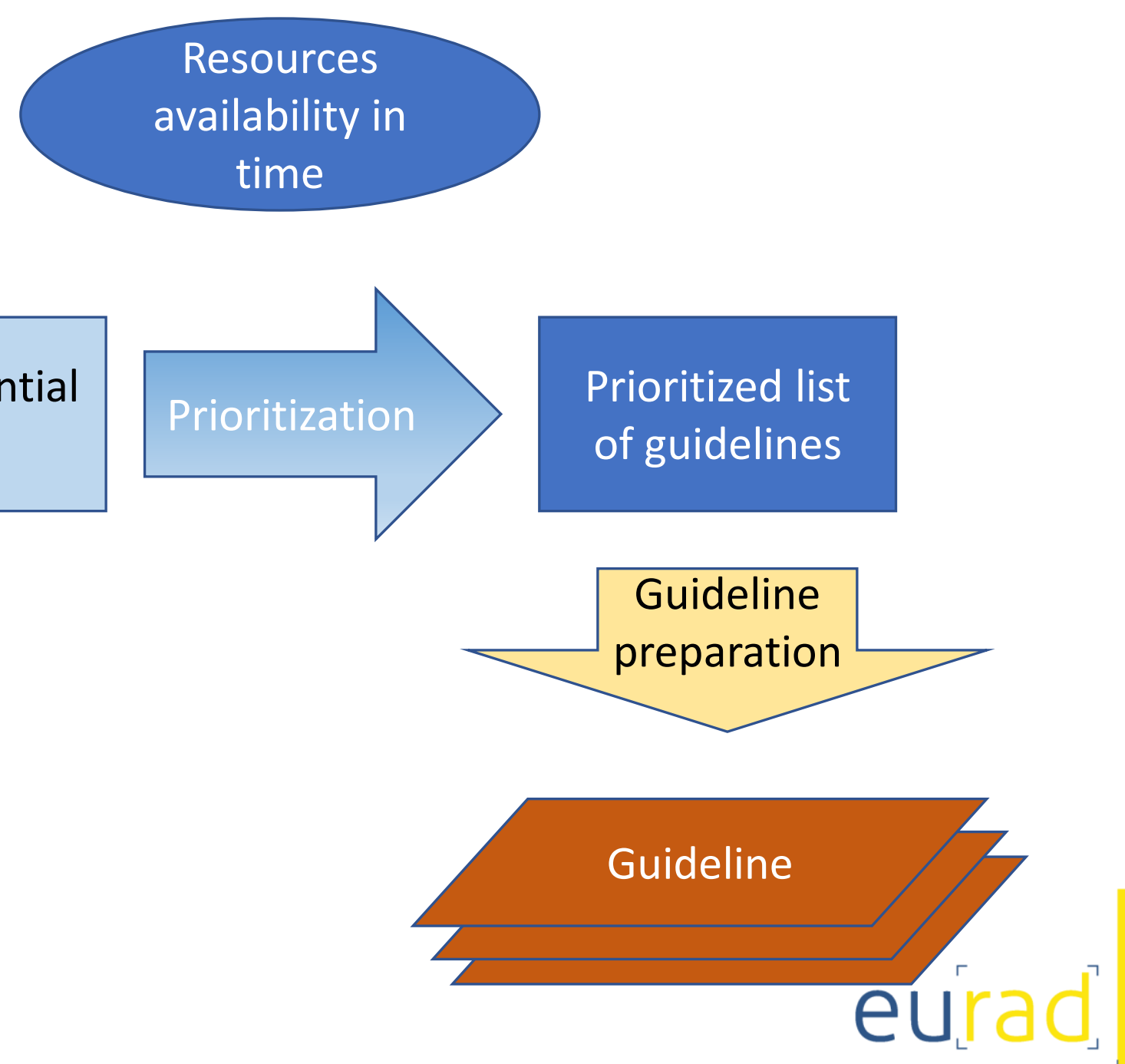


\section{THE DOCUMENTS - WHAT'S IN?}
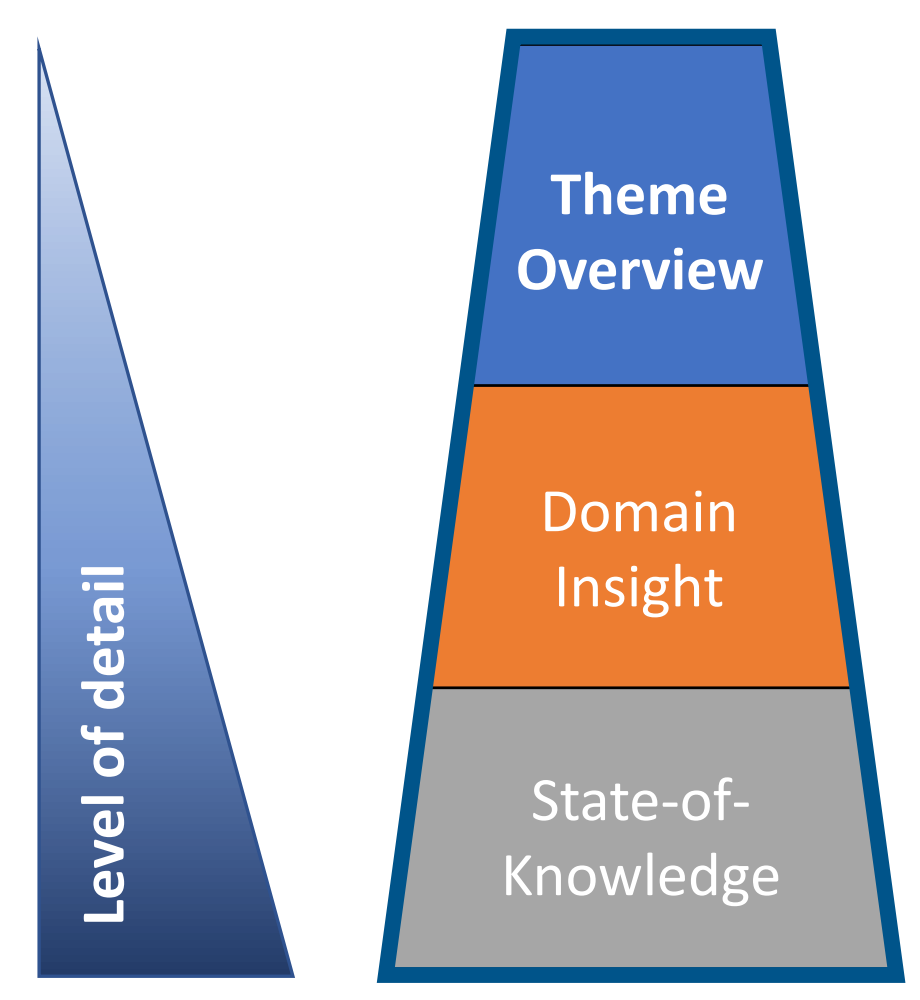

\section{Theme Overview}

Broad description of programme goals and typical activities for each theme and how they evolve over the phases of implementation

\section{Domain Insight}

Context documents that provide direct links for each knowledge domain to safety and implementation goals related to DGR requirements

\section{State-of-Knowledge}

Experts' view of the most relevant knowledge and associated uncertainties in a specific domain applied in the context of a radioactive waste management programme 


\section{THE DOCUMENTS - EXEMPLARY INSIGHT}

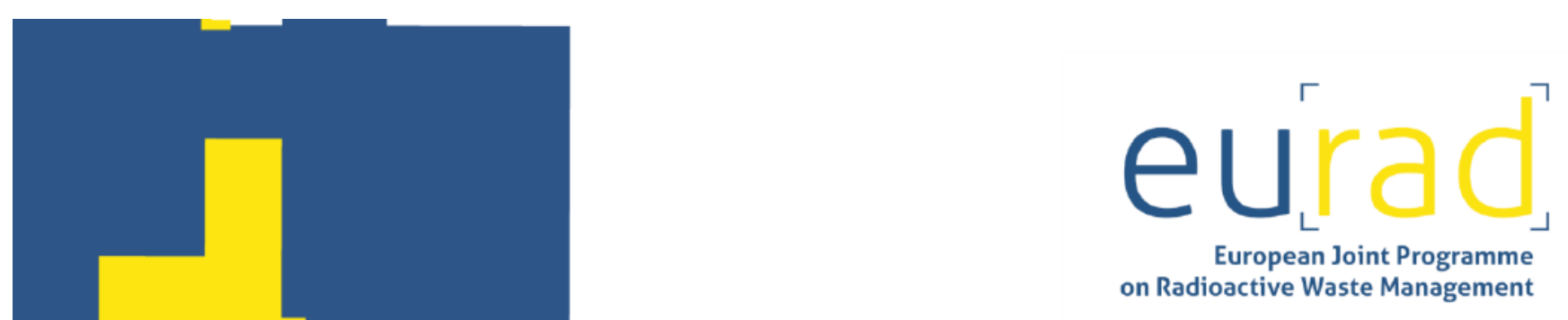

4. GEOSCIENCE; THEME OVERVIEW Host rock and geological environment for a DGR

Geoscience is of key importance for geological disposal of long-lived, higher activity radioactive waste. It is linked with all (EURAD) safety functions, i.e., isolation of waste from people and accessible biosphere, containment, retention and retardation of contaminants, minimized water flow and long-term geological contaility. A broad rakical will foll. A the ro ste of will follow the role of, and the work done in geoscience, with great interest through all the phases of a deep geological disposal project described in the EURAD Road Map. Permanent, clear and transparent communication is therefore a prerequisite for gaining broad acceptance of a deep geological disposal project.

KEYWORDS: Geological environment, Geological setting, Groundwater.

KEY ACRONYMS: Host Rock (HR), Site Descriptive Model (SDM)

Contributing authors: Andreas GAUTSCHI; Neil CHAPMAN. 


\section{MAKING KNOWLEDGE AVAILABLE}

\section{EURAD homepage}

- Final and approved PDF documents are available here: https://www.ejp-eurad.eu/roadmap

2. EURAD-Wiki

- EURAD internal

- More functionalities than the homepage:

- Commenting and Discussion functions

\section{Development of EURAD KM-portal / IT-tool}

1. Basis laid with study "Screening and review of existing/available knowledge management approaches and/or tools" (in review) - learning from well experienced experts, considering lessons learnt

2. Exploration of needs and available options 


\section{Main Page}

Main page
List of all don

List of all domains

Recent changes
Random page

Random page

Help about MediaWik

EURAD Homepag

Tools

What links here

Related changes
Upload file

Special pages

Special pages
Printable version

Permanent link

Page information

Cite this page

Get shortened U

Administration

Manage this wiki's core
settings

Manage this wik's
extensions

Manage this wiki's
namespaces

Manage this wiki's
permissions

Manage this wiki's
additional settings

Manage/Download this
wiki's dump

Welcome to the EURAD Roadmap Wiki!

This Wiki is still under Construction! All Feedback and comments highly appreciated!

To get an idea of the overall concept, check out the best developed hierarchy line Theme 3: Engineered Barrier System - Sub-Theme 3.7wanteform includes the Theme Overiew, Domains Insight, and State-of-Knowledge document.

\section{For a external visitor of this wiki}

Hello, we are still working on this Main Page, so this wiki remains private until it is ready. So please check this page again later!

Thematic Goals Breakdown Structure (GBS) [edit]

A generic roadmap for implementing radioactive waste management, leading to geological disposal

The roadmap describes typical programme goals, activities and capabilities needed against 7 themes, which are each further broken down into sub-themes and domains in what we call the "Goals Break lown Structure (GBS)". This matrix of phases vs. thematic goals provides a tiered and common framework allowing users to 'click in' and access existing knowledge. It is goals oriented to knowledge and competencies most critical for implementation, aligned to the EUF AD Vision.

- Theme 1: National Programme Management

- Theme 2: Pre-disposal

- Theme 3: Engineered Barrier System (Draft version)

- Theme 4: Geoscience

- Theme 5: Design and Optimisation

- Theme 6: Siting and Licensing (Draft version)

- Theme 7: Safety Case

Show a list of all Domains (Quick access)

What is new?

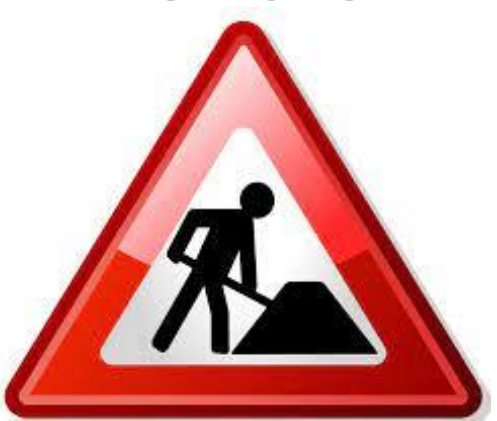

If you want to learn more about the EURAD Roadmap: The Roadmap User Guide (Issue 2)巴 can be found on the EURAD homepage Roadmap sections. All finalised and published EURAD KM docum! nts will also be available to all (also external viewers) on the EURAD homepage Roadmap sections. (These links will by default open in this tab. Open in new tab or window to keep the Wiki open)

If you want to dicuss and comment in documents or the Roadmap, we invite you to use the discussion function in this Wiki (see button at the top) or got to the extern EURADSCHOOL discussion board for the Roadmap and EURAD activities巴s (thi) link brings you to the EURAD Forum and will by default open in this tab. Open in new tab or window to keep the Wiki open). You will need to register an account in the EURADSCHOOL discussivan hoard to enjoy full functionality. 


\section{REFLECTING OUR WORK AND APPROACH}

One key objective is to provide real content (asap), not (only) procedures but

- a systematic and structured manner is important to ensure effectiveness and quality

$>$ Parallelisation of WP activities, keeping it agile

$>$ Starting with pilots and demonstration cases, learning procedure

- Resources are not infinitely available

$>$ Facilitate involvement of experts

> Make more use of existing KM documents

$>$ Stepwise supplementation of KM SoK documents with additional knowledge (e.g. on safety function or natural analogues)

- An adequate review process might take its time

> Share final drafts on an EURAD Wiki for information and discussion

We have to consider the long term vision

$>$ Implement update processes and a sustainable system 


\section{WP11 STATE-OF-KNOWLEDGE + WP12 GUIDANCE - LONG TERM VISION}

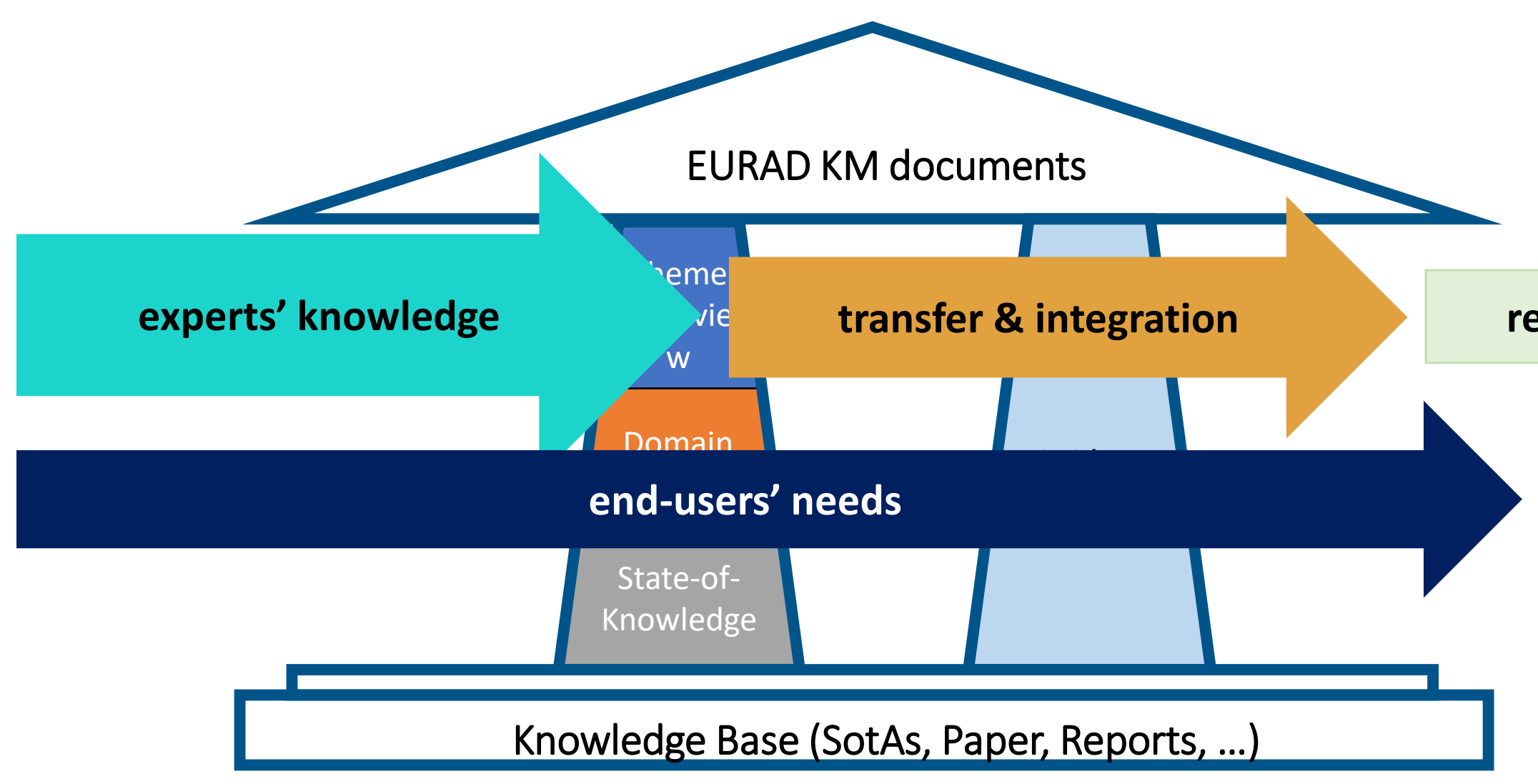

\section{reaching out to future}

Interest by national programs in a European long term vision and view of responsible organisations on the needs and scope will be essential for the continuation of EURAD towards EURAD2 


\section{KNOWLEDGE IS MORE THAN DOCUMENTS}

1

Roadmap

A common framework to structure knowledge

2 State of Knowledge

What we know and why its important

\section{Guidance}

Best practice and lessons learned

\section{Mobility \& Training}

Nuclear experience and know-how

5 Connecting people to people, and people to content

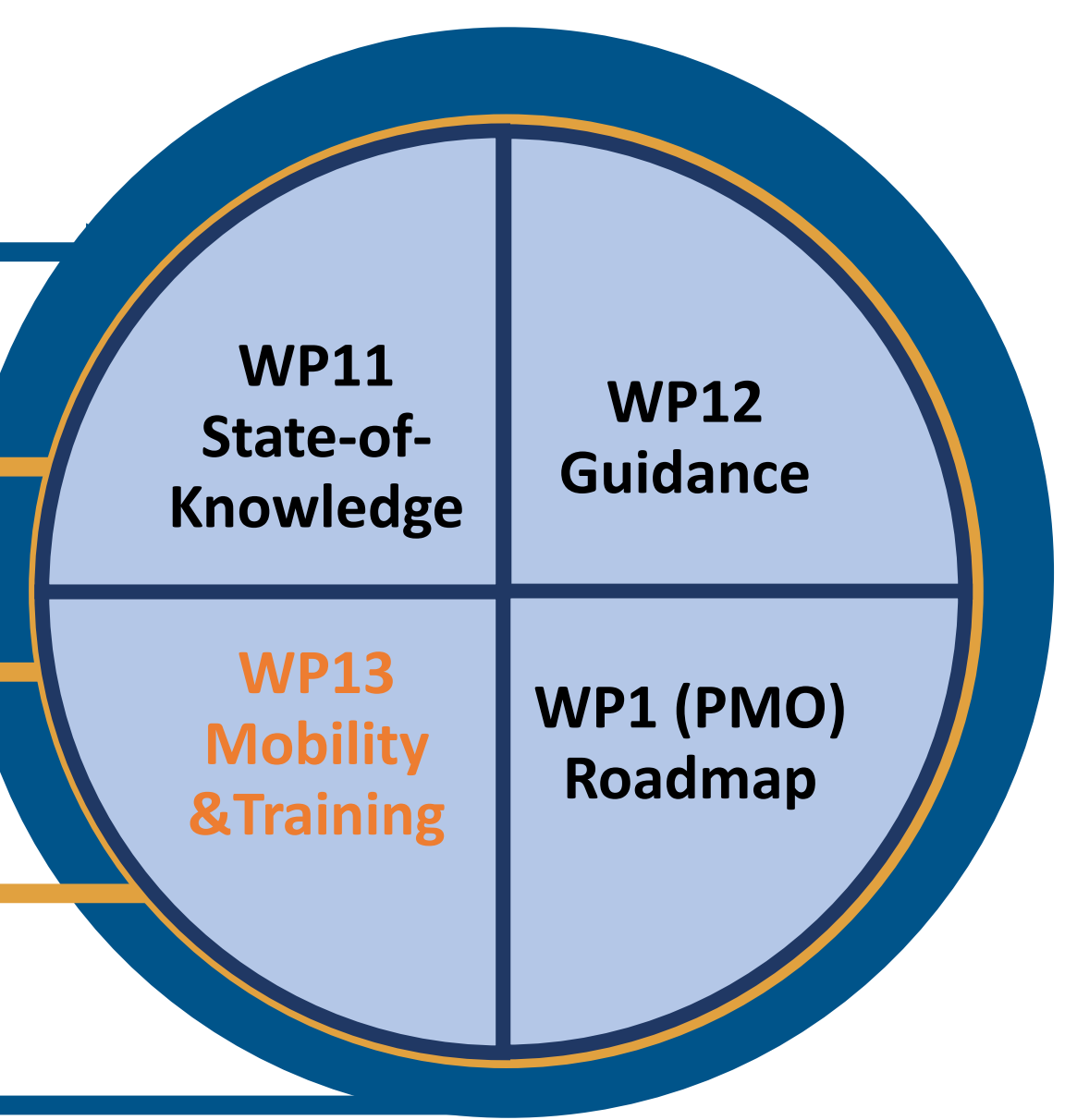




\section{eurad. \\ European Joint Programme on Radioactive Waste Management}

\section{THANK YOU FOR YOUR ATTENTION! QUESTIONS?}

\section{astrid.goebel@bge.de (BGE)}

